animals and man. When a dose of phenacetin was increased from $500 \mathrm{mg}$. to $2.5 \mathrm{~g}$. in human volunteers the formation and excretion of $p$-phenetidin and 2-hydroxyphenetidin sulphate were both enhanced. Neither of these is a metabolite of paracetamol. They concluded that, as a working hypothesis for further investigation to elucidate the pathogenesis of analgesic nephropathy, phenetidin deserved specia consideration. Prescott ${ }^{5}$ has commented that the metabolism, and possibly the toxicity of phenacetin, may be modified by the previous or concurrent administration of other drugs. There are therefore "logical reasons" for suggesting that the effect of paracetamol on the kidneys may well be different from that of phenacetin, particularly when phenacetin is consumed in large amounts.-We are, etc.

Joyce A. Abel. Robert A. MiLey.

Sterling-Winthrop Group Ltd.,
Surbiton, Surrey,

REFERENCES 1 Davies, D. J., Kennedy, A., and Roberts, C. Abrahams, C., and Levinson, C., South African Medical fournal, 1970, 44. 63.
Brown, D. M., and Hardy, T. L., British fournal of Pharmacology and Chemotherapy, 1968, 32 Klutch, A., Harfenist, M.. and Conney, A. H., Fournal of Medicinal Chemistry, 1966. 9, 63
Prescott, L. F., Sansur, M., Levin, W., and Conney, A. H. Clinical Pharmacology and
Therapeutics, 1968, 9. 605.

7 Shahidi N. T., Hospital Practice, 1968. 3. 73. Wochenschrift, 1969, 47, 1286.

\section{Treatment of Shock}

SIR,-In their recommendations for emergency treatment of myocardial infarction (3 October, p. 54) the physicians from the Chichester Postgraduate Medical Centre recommend intravenous injection of morphine $10 \mathrm{mg}$. or diomorphine $5 \mathrm{mg}$. Extensive experience with intravenous Cyclimorph convinces me that the emetic effects of morphine can be practically eliminated by the use of a harmless antiemetic such as cyclizine. I cannot see any reason for the continued practice of injecting plain morphine.

They also recommend that if there is hypotension the patient should be kept flat and the bed tilted head downwards. Although the Trendelenberg position is traditional for hypotensive shock ${ }^{1}$ the practical, theoretical, and experimental evidence indicates that a horizontal body with elevated limbs is the best position. The head down position will certainly produce immediate improvement compared with the upright posture because it results in the rapid transfer of blood from the limbs to the heart and vital organs.

But the head down position has two disadvantages compared with the horizontal position. Firstly, it causes the viscera to fall against the diaphragm, thus diminishing the volume of the chest, increasing the work of breathing and diminishing the negative pressure in the chest. ${ }^{2}{ }^{3}$ Secondly, it cannot increase the cerebral blood flow compared with the horizontal position because the arterial and venous pressures will be equally raised so that the theoretical net effect is nil. ${ }^{4}$ However, if the head down position is maintained for more than a short time it will result in oedema of the brain, which will diminish cerebral blood flow. ${ }^{5}$

These theoretical disadvantages are confirmed by experiments which demonstrate a higher mortality in the head down position, both in toxic hypotensive shock ${ }^{2}$ and in oligaemic hypotensive shock. ${ }^{6}$

We have learnt that, in the resting patient, blood flow in the leg is maximal when the limb is horizontal ${ }^{7}$; the absence of valves in the veins of the skull and neck suggest that this is even more valid in the case of the cerebral circulation. Since the aim of treatment in hypotensive shock is to diminish the circulation in the limbs and increase the circulation in the brain and vital organs without embarrassing respiration the rational treatment is to keep the body horizontal and elevate the limbs. ${ }^{8} 9$

It took us a long time to realize that heating up shocked patients was irrational and harmful. How long will it take us to abandon the tradition of tipping the shocked patient head downwards? Perhaps our greatest difficulty in abandoning the old treatment is the fact that most hospital beds and resuscitation trolleys are not equipped to facilitate elevation of the limbs while maintaining the body horizontal.-I am etc.,

\section{Bridgend General Hospital,
Bridgend, Glam.}

A. W. FowLER.

REFERENCES

London, P. S., A Practical Guide to the Care of the Injured, p. 19. Edinburgh, Livingstone, 1967. Surgery, Gynecology and Obstetrics, 1963, 116, 669.

Weil, M. H., Circulation, 1957, 16, 1097.

Re G. In Cardiac Arrest an Resuscitation. Ed. H. E. Stephenson. 2nd edn. p. 1Stivel. $P$.

J. Fournal of

Physiolory, 1955, 130, 467.
Weil M. H. In Cardiac Arrest and Resuscitation Ed. H. E. Stephenson. 2nd edn. St. Louis,

Mosby, 1964.
Beaconsfield, $P .$, and Ginsburg, J., Circulation Research, 1955, 3. 478 . Hardaway, R. M., Clinical Management of Shock, Stephenson, H. E. Ed. Cardiac Arrest and
Resuscitation. 2nd edn. St. Louis, Mosby. 1964.

\section{Allergy to Iprindole (Prondole) with Hepatotoxicity}

SIR,-In 1968 I had under my care probably the first case of iprindole hepatotoxicity. $\mathrm{He}$ was a young man who had been attending my outpatient clinic at the London Jewish Hospital for chronic anxiety and depression. This was kept under moderate control with amitryptyline and diazepam but because of a relapse in his condition I changed his medication to iprindole $15 \mathrm{mg}$ t.i.d. with diazepam $5 \mathrm{mg}$. t.i.d. on 24 October 1968. One month later when he came to see me again at my clinic he was jaundiced and investigations after admission revealed that this was a case of hepatotoxicity. His jaundice and liver dysfunction cleared up satisfactorily after three weeks. reported this case to the manufacturers of iprindole, John Wyeth \& Brother Ltd., and after studying the case records their scientific staff agreed with the diagnosis of drug toxicity.

However, despite this case, I have continued to use iprindole extensively, particularly with outpatients. I would disagree with Drs. D. F. Harrison and I. M. Stanley (7
November, p. 638) in their suggestion that this drug should be withdrawn by the manufacturers. It is a particularly useful tricyclic preparation in that it has so few side effects and is tolerated so well by most patients. In fact, with anxious patients it is one of the very few antidepressants that they will continue to take in full dosage without complaints of sluggishness, blurred vision, and dryness of the mouth. In the treatment of depressed and anxious patients we must weigh up the pros and cons of each treatment. Against the slight risk of jaundice must be weighed the real benefit to many patients from a drug such as iprindole, and therefore I strongly reject the suggestion that it should be withdrawn.-I am, etc.,

L. J. Clein.

Long Grove Hospital,
Epsom, Surrey.

SIR,-It would be interesting to know how many cases Drs. D. F. Harrison and I. M. Stanley have treated with iprindole for them to have found four cases of apparent allergic hepatotoxicity (7 November, p. 368).

My interest arises from the fact that I have used this tricyclic antidepressant very widely from the earliest days of its production, and while I have not kept formal note of the numbers of patients involved the relevant figure must certainly be little short of a thousand-and in no case have I observed this allergic effect. I am not disputing the causal relationship postulated in the cases quoted, but I would join issue with the suggestion that "as alternative tricyclic drugs are available with little or no evidence of adverse reactions, we would suggest that iprindole be withdrawn by the manufacturers."

For a start, surely the great attraction of iprindole lies in its freedom from side effects, as distinct from allergic phenomena. I know of no other tricyclic antidepressant with comparable freedom from atropine-like propensities. I think we should remember that the charges that Drs. Harrison and Stanley lay against iprindole have been acceptable occasional hazards of chlorpromazine for many years, and this preparation has certainly stood the test of time on its merits despite these. Even if the possibility of occasional allergic hepatotoxicity is accepted without reservation, this implies that the possibility of the rare occurrence of this phenomenon must be weighed against the undoubted value of a most acceptable (in terms of freedom from conventional side effects) drug, which at the worst is indicted with the production of an effect which reverses on withdrawal.

I would mention that I have regularly used iprindole $(15 \mathrm{mg}$. tab.) in dosage up to $180 \mathrm{mg}$. per day, and at the present time one of my patients, a depressive psychotic previously dependent upon maintenance E.C.T. for some time despite the exhibition of other antidepressants, is maintained at a reasonable level of freedom from symptoms with iprindole $105 \mathrm{mg}$. t.d.s. (315 mg. per day), without any side effects whatsoever In the light of this sort of experience I hope Drs. Harrison and Stanley will forgive my expression of concern at their suggestion that such a useful drug should no longer be 